\title{
Antiepileptic Drug Nonadherence and Its Predictors among People with Epilepsy
}

\author{
Asmamaw Getnet, ${ }^{1}$ Solomon Meseret Woldeyohannes, ${ }^{2}$ Lulu Bekana, ${ }^{3}$ \\ Tesfa Mekonen, ${ }^{4}$ Wubalem Fekadu, ${ }^{4}$ Melak Menberu, ${ }^{5}$ Solomon Yimer, ${ }^{6}$ \\ Adisu Assaye, ${ }^{7}$ Amsalu Belete, ${ }^{8}$ and Habte Belete ${ }^{4}$ \\ ${ }^{1}$ Finote Selam Hospital, Finote Selam, Ethiopia \\ ${ }^{2}$ Diseases Prevention and Control, School of Public Health, University of Queensland, Brisbane, QLD, Australia \\ ${ }^{3}$ Amanuel Mental Specialized Hospital, Addis Ababa, Ethiopia \\ ${ }^{4}$ College of Medicine and Health Sciences, Bahir Dar University, Bahir Dar, Ethiopia \\ ${ }^{5}$ College of Health Sciences, Mizan Tepi University, Mizan, Ethiopia \\ ${ }^{6}$ Psychiatry Department, College of Health Sciences and Medicine, Dilla University, Dilla, Ethiopia \\ ${ }^{7}$ Debre Markos University, Debre Markos, Ethiopia \\ ${ }^{8}$ College of Medicine and Health Sciences, Debre Tabor University, Debre Tabor, Ethiopia
}

Correspondence should be addressed to Tesfa Mekonen; smarthope1@gmail.com

Received 7 June 2016; Accepted 16 November 2016

Academic Editor: Jesus Pastor

Copyright (C) 2016 Asmamaw Getnet et al. This is an open access article distributed under the Creative Commons Attribution License, which permits unrestricted use, distribution, and reproduction in any medium, provided the original work is properly cited.

Introduction. Antiepileptic drugs are effective in the treatment of epilepsy to the extent that about $70 \%$ of people with epilepsy can be seizure-free, but poor adherence to medication is major problem to sustained remission and functional restoration. The aim of this study was to assess the prevalence and associated factors of antiepileptic drug nonadherence. Methods. Cross-sectional study was conducted on 450 individuals who were selected by systematic random sampling method. Antiepileptic drug nonadherence was measured by Morisky Medication Adherence Scale (MMAS) and logistic regression was used to look for significant associations. Result. The prevalence of AEDs nonadherence was 37.8\%. Being on treatment for 6 years and above [AOR $=3.47,95 \%$ CI: 1.88, 6.40], payment for AEDs [AOR = 2.76, 95\% CI: 1.73, 4.42], lack of health information [AOR = 2.20, 95\% CI: 1.41,3.43], poor social support $[\mathrm{AOR}=1.88,95 \%, \mathrm{CI}: 1.01,3.50]$, perceived stigma $[\mathrm{AOR}=2.27,95 \% \mathrm{CI}: 1.45,3.56]$, and experience side effect $[\mathrm{AOR}=1.70$, $95 \%$ CI: 1.06, 2.72] were significantly associated with antiepileptic drug nonadherence. Conclusion. More than one-third of people with epilepsy were not compliant with their AEDs. Giving health information about epilepsy and its management and consequent reduction in stigma will help for medication adherence.

\section{Introduction}

Epilepsy is a chronic disorder of the brain and is one of the most common serious neurological disorders affecting 50 million people worldwide with no boundary to age, race, social class, nationality, or geographical location $[1,2]$. Among patients who had epilepsy, $85 \%$ of them found in developing countries and estimated 40 million people do not receive appropriate treatment $[1,3]$. The overall mortality rate due to epilepsy increased by twofold to threefold as compared with the general population [4]. Medication nonadherence is a voluntary or involuntary behavior of medication intake which includes failing initially filling or refilling a prescription, discontinuing a medication before the course of therapy is completed, inability to adhere with agreed recommendations from health care provider, taking more or less of a medication than prescribed, and taking a dose at wrong time $[5,6]$.

The magnitude of antiepileptic drug nonadherence is ranged from $26 \%$ in USA to $67 \%$ in Nigeria $[7,8]$. As a study done in the North Carolina indicated, the prevalence of AEDs nonadherence was 39\% and it was higher (43\%) in elderly accompanied with increased likelihood hospitalization [9]. A primary care based study in UK showed that the prevalence of antiepileptic drug nonadherence was $36.4 \%$ and those who 
were on multidrug treatment were tend to be noncompliant with their treatment [10]. A study conducted in Finland indicated the prevalence of AEDs nonadherence as 34\% and nonadherence was higher in individuals who smoke cigarette and drink alcohol [11]. In sub-Saharan African countries, prevalence of antiepileptic drug nonadherence is significant which was about $67 \%$ in Nigeria, $54 \%$ in Kenya, and $37 \%$ in Ethiopia and financial factors were the significant predictors of nonadherence $[8,12-14]$.

Antiepileptic drugs (AEDs) are effective in the treatment of epilepsy, but poor adherence to medication is major problem to sustained remission and functional restoration resulted in treatment failure and seizure recurrence $[15,16]$. Even though around $70 \%$ of people who had epilepsy supposed to be seizure-free with optimum AED treatment, many people with epilepsy did not take their antiepileptic drugs appropriately and the mortality rate in nonadherent patients was more than threefold higher than that of adherent one [1719]. The consequence of AEDs nonadherence behavior has been associated with poor seizure control, increased morbidity and mortality along with increased time of hospitalization, worsened patient outcome, poor quality of life, and increased health care cost [20-23]. AEDs nonadherence will also lead to increase burden of inpatient and emergency department services; moreover, it also affects the family members socially, economically, and psychologically $[3,7,14,24]$.

There is scarcity of published information regarding the prevalence and associated factors of AEDs nonadherence in Ethiopia. A study which attempted to fill this information gap and came up with strong recommendation on possible interventions for improving medication adherence behavior among people with epilepsy is very important. Poor adherence to antiepileptic drugs is one of many reasons for pharmacological treatment failure and recurrence of seizure and consequently results in poor quality of life, decreased productivity, and seizure related social and economic crisis. Therefore this study was aimed at assessing the prevalence and associated factors of antiepileptic drug nonadherence among people with epilepsy.

\section{Methods}

Institution based cross-sectional study design was conducted from May 11 to June 8, 2015. The study was conducted on two hospitals in Northwest Ethiopia (Debre Markos Referral Hospital and Finote Selam District Hospital). Both hospitals provide service for more than 3.6 million population and there were around 1120 people with epilepsy who had followup in both hospitals. Adult individuals (18 and above years of age) who were diagnosed for epilepsy and have been on AEDs treatment for at least three months were included in the study and individuals who were unable to communicate due to serious neurological deficit and other serious illness were excluded.

The total sample for the study was 459, proportionally allocated for both hospitals (274 for Debre Markos Referral Hospital and 185 for Finote Selam District Hospital) and selected by systematic random sampling technique. The outcome variable for this study was antiepileptic drug nonadherence and the independent variables were as follows: sociodemographic variables: age, sex, marital status, ethnicity, religion, wealth index, educational status, occupation, and place of residence; patient and treatment related factors: perceived stigma, substance use, social support, AED type, drug side effects, duration of treatment, comorbid illness, and number of medications.

Data were collected by interviewing participants and reviewing patient charts using structured and pretested questionnaire by trained data collectors. AEDs nonadherence was measured by an eight-item Morisky Medication Adherence Scale (MMAS). A modified MMAS- 8 item was developed from the original MMAS-4 during 2008 by Morisky and his colleagues. The first seven items are dichotomous response categories with yes or no and the last item is five-point Likert scale response [12, 25-27]. Social support was assessed by using the Oslo 3-items social support scale; the first item is 4point Likert scale and the other two items are 5-point Likert scale. The sum score of this scale is ranged from minimum of 3 to the maximum 14, which is categorized into poor support 3-8, moderate support 9-11, and strong support 12-14 [28]. Felt stigma towards epilepsy was measured by using Kilifi stigma scale of epilepsy and the score above 10 indicated presence of perceived stigma [29].

The coded data entered into EPI INFO software version 3.5.3 and exported to SPSS version 20 for analysis. Descriptive statistics were used to describe the data. Bivariate and multivariable logistic regression were used to ascertain the association between covariates and the dependent variable. Odds ratios along with the $95 \%$ confidence intervals were used to show the strength of associations and $p$ value of less than 0.05 was considered as statistically significant. Regarding wealth index analysis, variables which measure the urban and rural communities were selected and the frequency was checked and those variables with less than 10 frequencies were avoided. Principal component analysis was used and variables which extraction values $<0.5$ were excluded step by step starting from small extraction value until extraction value $\geq$ 0.5 . Finally all variables with extraction value of $\geq 0.5$ were analyzed in sum factors and rank wealth index according to Ethiopia Demographic and Health Survey [30].

Ethical clearance was obtained from University of Gondar and Amanuel mental specialized hospital Institutional Review Board (IRB). Participants were assured that if they want to refuse to participate, their care or dignity would not be compromised in any way since there was no relationship between participation and health or treatment outcome. Confidentiality was maintained by anonymous questionnaire and informed consent was obtained from each participant.

\section{Result}

From the total of 459 sample size, 450 participants were interviewed with the response rate of $98.04 \%$. The other 9 participants refuse the interview and are considered as nonrespondent. Among the study participants, 264 (58.7\%) were males and the median age of participants was 27 years with interquartile range 14. All of the participants were Amhara in 
TABLE 1: Sociodemographic characteristics of people with epilepsy, Ethiopia, $2015(n=450)$.

\begin{tabular}{|c|c|c|c|}
\hline Variables & Categories & Frequency $(n)$ & Percent (\%) \\
\hline \multirow{2}{*}{ Sex } & Male & 264 & 58.7 \\
\hline & Female & 186 & 41.3 \\
\hline \multirow{3}{*}{ Age } & $18-25$ & 210 & 46.7 \\
\hline & $26-44$ & 195 & 43.3 \\
\hline & 45 and above & 45 & 10 \\
\hline \multirow{4}{*}{ Marital status } & Single & 206 & 45.8 \\
\hline & Married & 167 & 37.1 \\
\hline & Divorced & 63 & 14 \\
\hline & Widowed & 14 & 3.1 \\
\hline \multirow{3}{*}{ Religion } & Protestant & 27 & 6 \\
\hline & Muslim & 30 & 6.7 \\
\hline & Orthodox & 393 & 87.3 \\
\hline Ethnicity & Amhara & 450 & 100 \\
\hline \multirow{3}{*}{ Occupation } & $\begin{array}{l}\text { Self/private } \\
\text { employed }\end{array}$ & 274 & 60.9 \\
\hline & Jobless & 144 & 32 \\
\hline & $\begin{array}{c}\text { Government } \\
\text { employee }\end{array}$ & 32 & 7.1 \\
\hline \multirow{4}{*}{$\begin{array}{l}\text { Educational } \\
\text { status }\end{array}$} & $\begin{array}{l}\text { Unable to read and } \\
\text { write }\end{array}$ & 201 & 44.7 \\
\hline & Primary school & 149 & 33.1 \\
\hline & Secondary school & 50 & 11.1 \\
\hline & Diploma and above & 50 & 11.1 \\
\hline \multirow{5}{*}{ Wealth index } & Lowest & 87 & 19.3 \\
\hline & Second & 91 & 20.2 \\
\hline & Middle & 101 & 22.4 \\
\hline & Fourth & 103 & 22.9 \\
\hline & Highest & 68 & 15.1 \\
\hline \multirow{2}{*}{ Residence } & Rural & 338 & 75.1 \\
\hline & Urban & 112 & 24.9 \\
\hline
\end{tabular}

ethnicity and 393 (87.3\%) were orthodox in religion. From total participants, 206 (45.8\%) were single followed by 167 (37.1\%) married. More than half of the participants 274 (60.9\%) were self/private employed and 201 (44.7\%) participants were unable to read and write. From the participants, $87(19.3 \%)$ and $68(15.1 \%)$ had lowest and highest wealth index respectively, and majority of respondents 338 (75.1\%) predominantly resided in the rural areas (see Table 1).

\section{Clinical and Patient Related Factors}

Majority of the respondents, 345 (76.7\%), were on monotherapy and Phenobarbital was the most commonly prescribed AED. Comorbid illness (depression, HIV, dyspepsia, schizophrenia, and asthma) was reported by 28 (6.2\%) participants and majority of the participants 329 (73.1\%) were treated for epilepsy for at least 2 years. More than one-third of
TABLE 2: Distribution of patients with epilepsy disorder by clinical and treatment related factors, Ethiopia, $2015(n=450)$.

\begin{tabular}{|c|c|c|c|}
\hline Variables & Category & Frequency & Percent (\%) \\
\hline \multirow{4}{*}{ Current AEDs } & Phenobarbital & 408 & 90.7 \\
\hline & Phenytoin & 64 & 14.2 \\
\hline & Sodium-valproate & 30 & 6.7 \\
\hline & Carbamazepine & 54 & 12 \\
\hline \multirow{2}{*}{$\begin{array}{l}\text { Number of AEDs } \\
\text { prescribed }\end{array}$} & One & 345 & 76.7 \\
\hline & Two & 105 & 23.3 \\
\hline \multirow{2}{*}{ Comorbid illness } & No & 422 & 93.8 \\
\hline & Yes & 28 & 6.2 \\
\hline \multirow{2}{*}{ Reported side effects } & No & 323 & 71.8 \\
\hline & Yes & 127 & 28.2 \\
\hline \multirow{3}{*}{$\begin{array}{l}\text { Duration on } \\
\text { treatment }\end{array}$} & 3 months-1 year & 121 & 26.9 \\
\hline & 2 years -5 years & 193 & 42.9 \\
\hline & 6 years $\&$ above & 136 & 30.2 \\
\hline \multirow{2}{*}{ Getting medication } & Freely & 165 & 36.7 \\
\hline & By payment & 285 & 63.3 \\
\hline \multirow{2}{*}{$\begin{array}{l}\text { Getting health } \\
\text { information }\end{array}$} & Yes & 289 & 64.2 \\
\hline & No & 161 & 35.8 \\
\hline \multirow{2}{*}{ Ever substance use } & No & 405 & 90 \\
\hline & Yes & 45 & 10 \\
\hline \multirow{2}{*}{$\begin{array}{l}\text { Current substance } \\
\text { use }\end{array}$} & No & 428 & 95.1 \\
\hline & Yes & 22 & 4.9 \\
\hline \multirow{2}{*}{ Perceived stigma } & No & 293 & 65.1 \\
\hline & Yes & 157 & 34.9 \\
\hline \multirow{3}{*}{ Social support } & Poor social support & 128 & 28.4 \\
\hline & $\begin{array}{c}\text { Moderate social } \\
\text { support }\end{array}$ & 219 & 48.7 \\
\hline & $\begin{array}{l}\text { Strong social } \\
\text { support }\end{array}$ & 103 & 22.9 \\
\hline
\end{tabular}

the participants reported that they did not get health information about their condition and side effects of AEDs; and 127 (28.2\%) of the participants experienced side effect of AEDs, most frequently sedation. Perceived epilepsy related stigma was also experienced by $34.9 \%$ of people with epilepsy (see Table 2).

\section{Prevalence and Associated Factors of Antiepileptic Drug Nonadherence}

The overall prevalence of antiepileptic drug nonadherence among the study participants was $37.8 \%$. During multivariate analysis of AEDs nonadherence in relation to all associated variables, ways of getting medications (free of charge or with payment), status of getting health information from health care providers, social support, perceived epilepsy related stigma, presence of antiepileptic medication side effects, and duration of the treatment were significantly associated (see Table 3). 
TABLE 3: Factors associated with antiepileptic drug nonadherence among people with epilepsy, Ethiopia, 2015 ( $n=450)$.

\begin{tabular}{|c|c|c|c|c|}
\hline \multirow{2}{*}{ Independent variables } & \multicolumn{2}{|c|}{ AEDs nonadherence } & \multirow{2}{*}{ COR (95\% CI) } & \multirow{2}{*}{$\operatorname{AOR}(95 \% \mathrm{CI})$} \\
\hline & No & Yes & & \\
\hline \multicolumn{5}{|l|}{ Co morbid illness } \\
\hline No & 266 & 156 & 1 & 1 \\
\hline Yes & 14 & 14 & $1.71(0.79-3.67)$ & $1.29(0.53,3.10)$ \\
\hline \multicolumn{5}{|l|}{ Reported side effect } \\
\hline No & 216 & 107 & 1 & 1 \\
\hline Yes & 64 & 63 & $1.99(1.31-3.02)$ & $1.70(1.06,2.72)$ \\
\hline \multicolumn{5}{|l|}{ Getting medication } \\
\hline Free & 125 & 40 & 1 & 1 \\
\hline Payment & 155 & 130 & $2.62(1.71-4.01)$ & $2.76(1.73,4.42)$ \\
\hline \multicolumn{5}{|l|}{ Getting health information } \\
\hline No & 77 & 84 & $2.58(1.73-3.84)$ & $2.20(1.41,3.43)$ \\
\hline Yes & 203 & 86 & 1 & 1 \\
\hline \multicolumn{5}{|l|}{ Ever substance use } \\
\hline no & 258 & 147 & 1 & 1 \\
\hline Yes & 22 & 23 & $1.84(0.99-3.41)$ & $1.35(0.67,2.73)$ \\
\hline \multicolumn{5}{|l|}{ Duration on treatment } \\
\hline 3 months -1 year & 96 & 25 & 1 & 1 \\
\hline 2 years -5 years & 117 & 76 & $2.49(1.47-4.22)$ & $2.32(1.31,4.10)$ \\
\hline 6 years and above & 67 & 69 & $3.96(2.27-6.88)$ & $3.47(1.88,6.40)$ \\
\hline \multicolumn{5}{|l|}{ Social support } \\
\hline Poor social support & 58 & 70 & $3.23(1.85-5.64)$ & $1.88(1.01,3.50)$ \\
\hline Moderate social support & 147 & 72 & $1.31(0.78-2.20)$ & $1.04(0.59,1.83)$ \\
\hline Strong social support & 75 & 28 & 1 & 1 \\
\hline \multicolumn{5}{|l|}{ Perceived stigma } \\
\hline No & 209 & 84 & 1 & 1 \\
\hline Yes & 71 & 86 & $3.01(2.01-4.51)$ & $2.27(1.45,3.56)$ \\
\hline
\end{tabular}

\section{Discussion}

Nonadherence to treatment is one of many reasons for pharmacological treatment failure and seizure recurrence. AEDs nonadherence was assessed by an eight-item Morisky Medication Adherence Scale. Its sensitivity and specificity were $93 \%$ and $53 \%$, respectively, and the participant was considered as nonadherent to AEDs if the score of MMAS was 2 or more scales $[25,26]$. In this study, the prevalence of antiepileptic drug nonadherence among people with epilepsy was $37.8 \%$ with $95 \%$ CI $(33.3 \%$; $42.3 \%)$.

The finding of this study was consistent with the studies conducted in North Carolina 39\%, Finland 34\%, and UK $36.4 \%$ [9-11]. However, it was greater than the study done in USA $26 \%$ and the probable explanation might be the differences in study design (retrospective cohort in USA) and socioeconomic differences [7]. The finding of this study was lower than the studies done in Brazil, Nigeria, and Palestine which were $66.2 \%, 67.4 \%$, and $64 \%$, respectively, and this difference was probably due to the difference in AEDs multidrug treatment. For instance, $71.1 \%$ of people with epilepsy in Brazil, 85\% in Nigeria, and 63.2\% in Palestine were on multiple AEDs treatment while in the current study, only $23.3 \%$ of people with epilepsy were in poly-AEDs treatment $[25,31,32]$.

People with epilepsy who were buying AEDs were about 2.76 times more likely as to be nonadherent as compared with those who were getting their AEDs free of charge $[\mathrm{AOR}=2.76,95 \%, \mathrm{CI}: 1.73,4.42]$. The long-term nature of epilepsy treatment might contribute for this association; buying medications for long period of time lets the individual to feel bored about his condition and consequently end up in nonadherence. The finding was supported by the study from Kenya [12]. Individuals who did not get health information about their illness, duration of treatment, and drug side effect were about 2.2 times more likely to be nonadherent than their counterparts $[\mathrm{AOR}=2.20,95 \%, \mathrm{CI}: 1.41,3.43]$. Unless they got sufficient information, people with epilepsy tends to stop taking AEDs immediately after the seizure has been controlled or whenever they experience side effects [13].

Concerning social support, participants who had poor social support were 1.88 times more likely to be nonadherent as compared with those who had strong social support 
[AOR $=1.88,95 \%$, CI: 1.01, 3.50]. Favorable perception for social support had positive correlation to be adherent with drugs and this finding was supported by other studies $[13,33]$. Regarding duration of treatment, those people with epilepsy who were being on treatment for 6 years and above were 3.47 times more likely to be nonadherent as compared with participants who were on treatment for 3 months to 1 year $[\mathrm{AOR}=3.47,95 \%, \mathrm{CI}: 1.88,6.40]$ and being on treatment for $2-5$ years who were 2.32 times more likely to be nonadherent as compared with their counterparts $[\mathrm{AOR}=2.32,95 \%$, CI: 1.31, 4.10]. The present study showed that as treatment duration increases, the participants became more likely to be nonadherent and this is supported by other studies [12, 13].

The odds of being nonadherent for participants who had perceived epilepsy related stigma were 2.27 times [AOR = $2.27,95 \%$, CI: $1.45,3.56$ ] as compared to those who had not. The actual physical act of having to take medication can increase the levels of stigma experienced by the person with epilepsy and taking AEDs reminds the individuals that they have epilepsy and they may keep pill-taking in public to the minimum resort $[34,35]$. Those participants who had AEDs side effect were 1.70 [AOR $=1.70,95 \%, \mathrm{CI}$ : 1.06, 2.72] times more likely to be nonadherent as compared with those who had no AEDs side effect. As indicated by different studies, most complaints of people with epilepsy are related with medication side effects and is probably the commonest cause for discontinuing AEDs without consulting the health care giver $[35,36]$.

\section{Conclusion}

The prevalence of antiepileptic drug nonadherence among patients with epilepsy was high. AEDS nonadherence was significantly associated with variables like availability of health information, epilepsy related stigma, presence of social support, AEDs side effects, duration of the treatment, and ways of getting AEDs (free of charge or with fee). Giving brief psychoeducation about epilepsy, AEDs side effect and the importance of sticking with the recommended drug use can improve AEDs adherence. Information dissemination to the people with epilepsy and to the public at large is important to prevent AEDs nonadherence and to promote healthy life for those individuals.

\section{Competing Interests}

All authors declared that they have no conflict of interests regarding the publication of this paper.

\section{Authors' Contributions}

Asmamaw Getnet conceived the original idea, developed the proposal, designed the study, collected the data, analyze and interpret the finding, prepared the manuscript, and participated in all stages of the research. Solomon Meseret Woldeyohannes and Lulu Bekana participated in the original conception of the idea. Solomon Meseret Woldeyohannes,
Lulu Bekana, Tesfa Mekonen, Wubalem Fekadu, Melak Menberu, Solomon Yimer, Adisu Assaye, Amsalu Belete, and Habte Belete participated in proposal development, design, analysis and interpretation, data collection, preparation of the manuscript, and all stages of the research.

\section{Acknowledgments}

The authors like to acknowledge the study participants for their precious time and genuine cooperation and Amanuel Mental Specialized Hospital for the financial support.

\section{References}

[1] World Health Organization, Neurological Disorders: Public Health Challenges, World Health Organization, Geneva, Switzerland, 2006.

[2] E. Stump, "WHO report: millions have neurological disorders worldwide," Neurology Today, vol. 7, no. 7, 2007.

[3] World Health Organization, Atlas: Epilepsy Care in the World, WHO, Geneva, Switzerland, 2005.

[4] M. F. O'Donoghue and J. W. A. S. Sander, "The mortality associated with epilepsy, with particular reference to sudden unexpected death: a review," Epilepsia, vol. 38, supplement 11, pp. S15-S19, 1997.

[5] L. Osterberg and T. Blaschke, "Adherence to medication," The New England Journal of Medicine, vol. 353, no. 5, pp. 487-497, 2005.

[6] J. G. Hugtenburg, L. Timmers, P. J. M. Elders, M. Vervloet, and L. van Dijk, "Definitions, variants, and causes of nonadherence with medication: a challenge for tailored interventions," Patient Preference and Adherence, vol. 7, pp. 675-682, 2013.

[7] R. E. Faught, J. R. Weiner, A. Guérin, M. C. Cunnington, and M. S. Duh, "Impact of nonadherence to antiepileptic drugs on health care utilization and costs: findings from the RANSOM study," Epilepsia, vol. 50, no. 3, pp. 501-509, 2009.

[8] O. S. Johnbull, B. Farounbi, A. O. Adeleye, O. Ogunrin, and A. P. Uche, "Evaluation of factors influencing medication adherence in patients with epilepsy in rural communities of Kaduna State, Nigeria," Neuroscience \& Medicine, vol. 2, no. 4, pp. 299-305, 2011.

[9] K. L. Davis, S. D. Candrilli, and H. M. Edin, "Prevalence and cost of nonadherence with antiepileptic drugs in an adult managed care population," Epilepsia, vol. 49, no. 3, pp. 446-454, 2008.

[10] S. C. E. Chapman, R. Horne, A. Chater, D. Hukins, and W. H. Smithson, "Patients' perspectives on antiepileptic medication: relationships between beliefs about medicines and adherence among patients with epilepsy in UK primary care," Epilepsy and Behavior, vol. 31, pp. 312-320, 2014.

[11] H. Kyngäs, "Compliance with health regimens of adolescents with epilepsy," Seizure, vol. 9, no. 8, pp. 598-604, 2000.

[12] C. K. Mbuba, A. K. Ngugi, G. Fegan et al., "Risk factors associated with the epilepsy treatment gap in Kilifi, Kenya: a cross-sectional study," The Lancet Neurology, vol. 11, no. 8, pp. 688-696, 2012.

[13] E. T. El-Shamaa, "Factors contributing to therapeutic compliance of epileptic patients and the suggestive solutions," Journal of Biology, Agriculture and Healthcare, vol. 3, no. 3, pp. 22-35, 2013. 
[14] H. Getachew, N. Dekema, S. Awol, A. Abdi, and M. Mohammed, "Medication adherence in epilepsy and potential risk factors associated with non adherence in tertiary care teaching hospital in southwest Ethiopia," Gaziantep Medical Journal, vol. 20, no. 1, pp. 59-65, 2014.

[15] P. A. Dekker and WHO, Epilepsy: A Manual for Medical and Clinical Officers in Africa, WHO, Geneva, Switzerland, 2002.

[16] E. Sabaté, Adherence to Long-Term Therapies: Evidence for Action, World Health Organization, Geneva, Switzerland, 2003.

[17] J. W. Sander, "The use of antiepileptic drugs-principles and practice," Epilepsia, vol. 45, no. 6, pp. 28-34, 2004.

[18] P. Kwan, S. C. Schachter, and M. J. Brodie, "Drug-resistant epilepsy," The New England Journal of Medicine, vol. 365, no. 10, pp. 919-926, 2011.

[19] H. Håkonsen and E. Toverud, "A review of patient perspectives on generics substitution: what are the challenges for optimal drug use," Generics and Biosimilars Initiative Journal, vol. 1, no. 1, pp. 28-32, 2012.

[20] A. Neligan, G. S. Bell, A. L. Johnson, D. M. Goodridge, S. D. Shorvon, and J. W. Sander, "The long-term risk of premature mortality in people with epilepsy," Brain, vol. 134, no. 2, pp. 388395, 2011.

[21] M. Kaddumukasa, M. Kaddumukasa, S. Matovu, and E. Katabira, "The frequency and precipitating factors for breakthrough seizures among patients with epilepsy in Uganda," BMC Neurology, vol. 13, article 182, 2013.

[22] J. A. Cramer, Z. J. Wang, E. Chang et al., "Healthcare utilization and costs in adults with stable and uncontrolled epilepsy," Epilepsy \& Behavior, vol. 31, pp. 356-362, 2014.

[23] C. A. Hovinga, M. R. Asato, R. Manjunath et al., "Association of non-adherence to antiepileptic drugs and seizures, quality of life, and productivity: survey of patients with epilepsy and physicians," Epilepsy \& Behavior, vol. 13, no. 2, pp. 316-322, 2008.

[24] H. H. Martins, N. B. Alonso, L. M. F. F. Guilhoto, M. S. B. Guaranha, and E. M. T. Yacubian, "Adherence to treatment in patients with juvenile myoclonic epilepsy: correlation with quality of life and adverse effects of medication," Journal of Epilepsy and Clinical Neurophysiology, vol. 15, no. 4, pp. 192-196, 2009.

[25] C. M. M. Ferrari, R. M. C. de Sousa, and L. H. M. Castro, "Factors associated with treatment non-adherence in patients with epilepsy in Brazil," Seizure, vol. 22, no. 5, pp. 384-389, 2013.

[26] D. E. Morisky, A. Ang, M. Krousel-Wood, and H. J. Ward, "Predictive validity of a medication adherence measure in an outpatient setting," The Journal of Clinical Hypertension, vol. 10, no. 5, pp. 348-354, 2008.

[27] D. E. Morisky, L. W. Green, and D. M. Levine, "Concurrent and predictive validity of a self-reported measure of medication adherence," Medical Care, vol. 24, no. 1, pp. 67-74, 1986.

[28] H. Bøen, "Characteristics of senior centre users-and the impact of a group Programme on social support and late-life depression," Norsk Epidemiologi, vol. 22, no. 2, pp. 261-269, 2012.

[29] C. Kathomi Mbuba, Epilepsy Treatment Gap, Associated Risk Factors and Intervention Strategies in Kilifi, Kenya, University of Basel, 2011.

[30] Ethiopian Central Statistics Agency and ICF International, Ethiopia Demographic and Health Survey 2011, CSA, Addis Ababa, Ethiopia, 2012.

[31] L. Nakhutina, J. S. Gonzalez, S. A. Margolis, A. Spada, and A. Grant, "Adherence to antiepileptic drugs and beliefs about medication among predominantly ethnic minority patients with epilepsy," Epilepsy \& Behavior, vol. 22, no. 3, pp. 584-586, 2011.

[32] W. M. Sweileh, M. S. Ihbesheh, I. S. Jarar et al., "Self-reported medication adherence and treatment satisfaction in patients with epilepsy," Epilepsy \& Behavior, vol. 21, no. 3, pp. 301-305, 2011.

[33] A. J. Shallcross, D. A. Becker, A. Singh et al., "Psychosocial factors associated with medication adherence in ethnically and socioeconomically diverse patients with epilepsy," Epilepsy \& Behavior, vol. 46, pp. 242-245, 2015.

[34] J. Eatock and G. A. Baker, "Managing patient adherence and quality of life in epilepsy," Neuropsychiatric Disease and Treatment, vol. 3, no. 1, pp. 117-131, 2007.

[35] L. Virág, M. Murgaš, and M. Kuželová, "Pharmacotherapeutic adherence and quality of life in paediatric outpatients with epilepsy," Acta Facultatis Pharmaceuticae Universitatis Comenianae, vol. 59, supplement 6, pp. 76-83, 2012.

[36] J. A. Carpay, A. P. Aldenkamp, and C. A. van Donselaar, "Complaints associated with the use of antiepileptic drugs: results from a community-based study," Seizure-European Journal of Epilepsy, vol. 14, no. 3, pp. 198-206, 2005. 


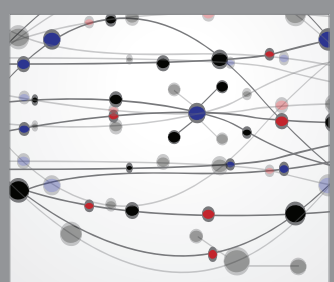

The Scientific World Journal
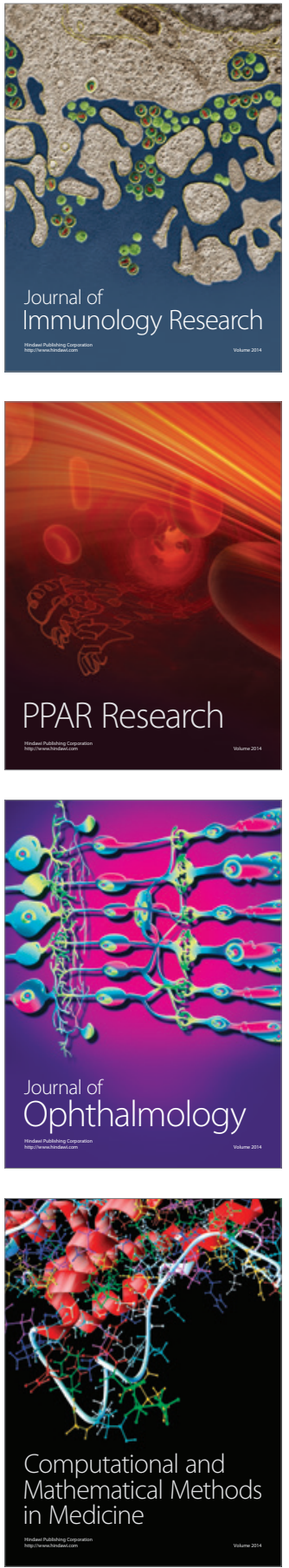

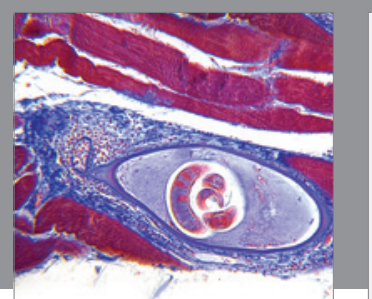

Gastroenterology Research and Practice

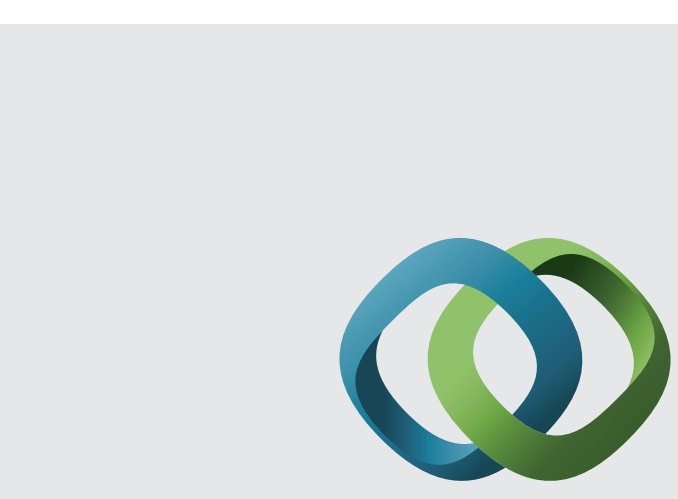

\section{Hindawi}

Submit your manuscripts at

http://www.hindawi.com
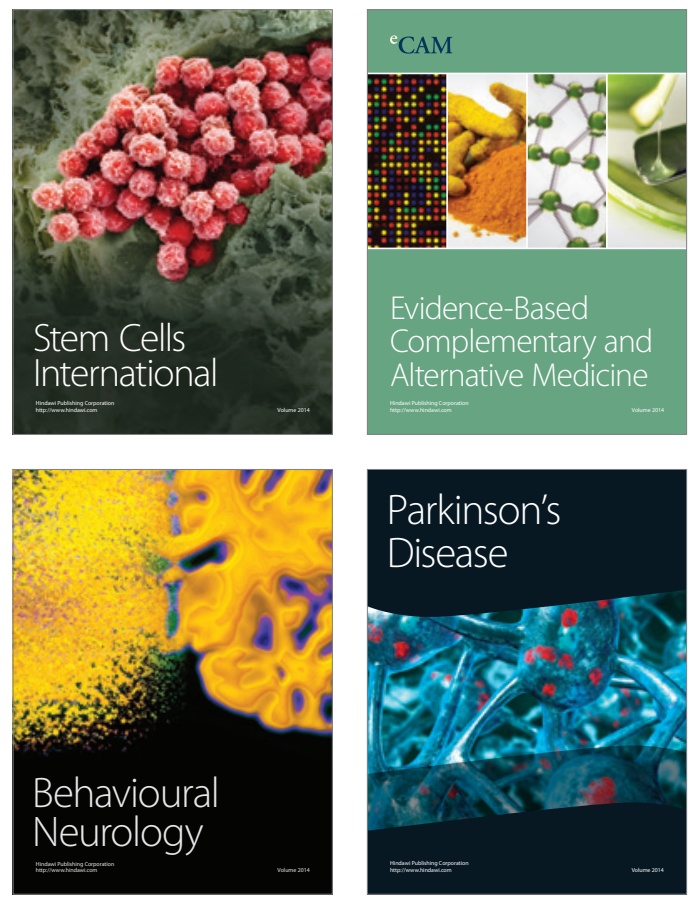
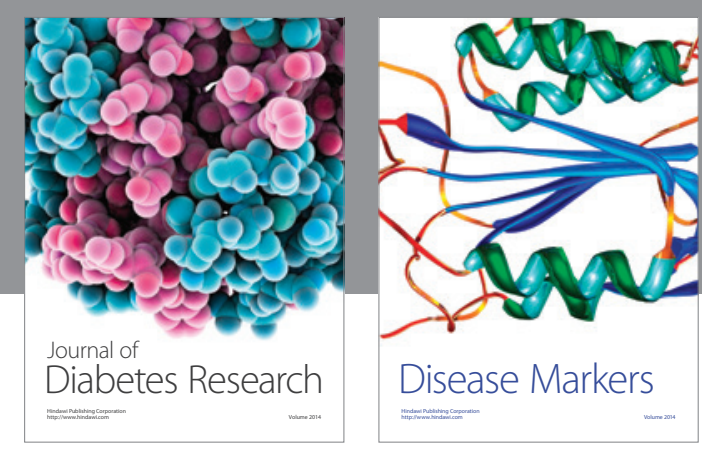

Disease Markers
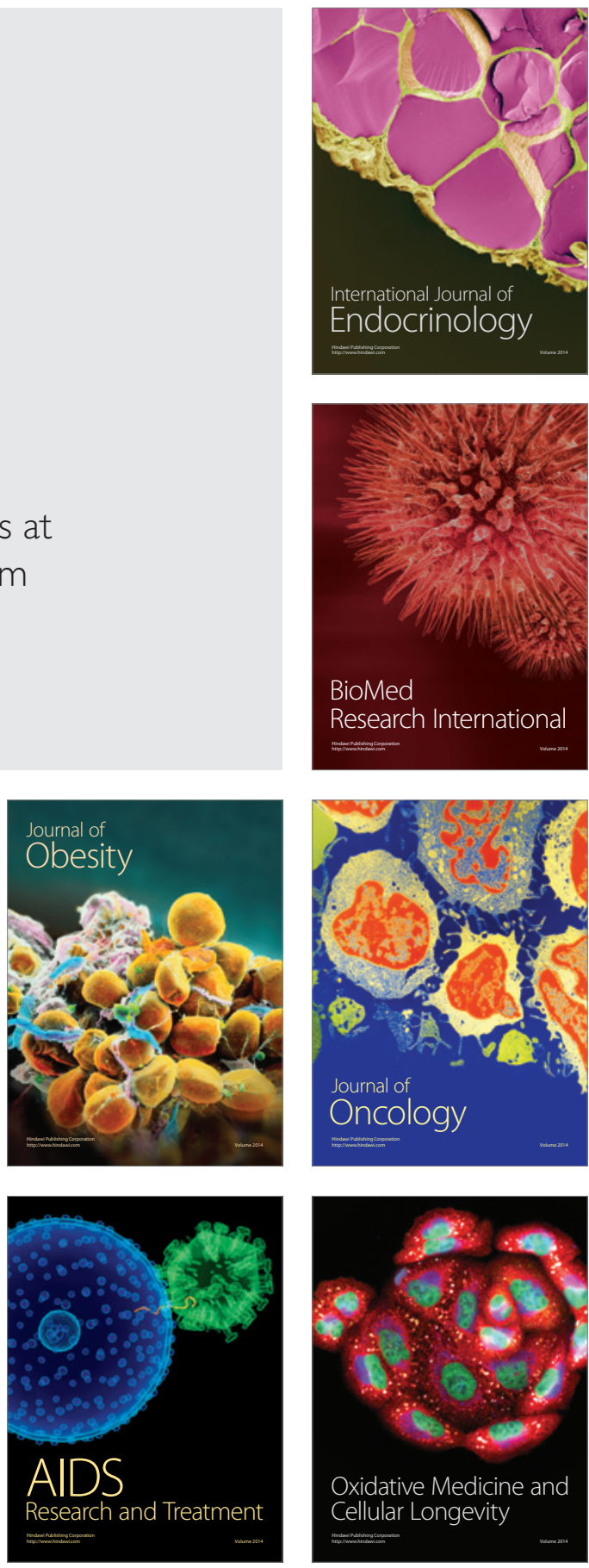